\title{
Implementation of natural disturbance-based management in northern British Columbia
}

\author{
by S. Craig DeLong ${ }^{1}$
}

\begin{abstract}
Ecologically based landscape units and associated characteristics of natural disturbance (e.g., seral stage and patch size distribution) were recently developed for the northeast corner of British Columbia and used as the basis for establishing guidance and policy for natural disturbance-based management for two large timber supply areas. I discuss the development of the landscape units; development of guidance for the units; and implementation of the guidance for old forest, interior old forest, and early seral patch size objectives. This paper demonstrates how natural-disturbance-based management can be successfully implemented.
\end{abstract}

Key words: natural-disturbance-based management, natural range of variability, seral stage distribution, old-forest requirements, patch size, guidance, implementation

\section{RÉSUMÉ}

Des unités découlant de l'écologie du milieu et les caractéristiques associées aux perturbations naturelles (par ex. l'évolution selon la série et la distribution de la taille des parcelles) ont été élaborées dernièrement pour la partie nord-est de la Colombie-Britannique et elles ont été utilisées en tant que référence pour la mise en place d'un guide et d'une politique en matière d'aménagement tiré des perturbations naturelles pour deux importantes zones d'approvisionnement en matière ligneuse. Je discute de l'élaboration des unités écosystémiques, du développement du guide pour les unités et de la mise place du guide pour les vieilles forêts, les vieilles forêts de l'Intérieur et des objectifs initiaux reliés à la taille des parcelles simulant la série naturelle. Cet article indique comment l'aménagement reposant sur les perturbations naturelles peut être mis en place avec succès.

Mots clés : aménagement reposant sur les perturbations naturelles, variabilité du domaine naturel, distribution de l'évolution sérique, besoins des vieilles forêts, taille des parcelles, guide, implantation

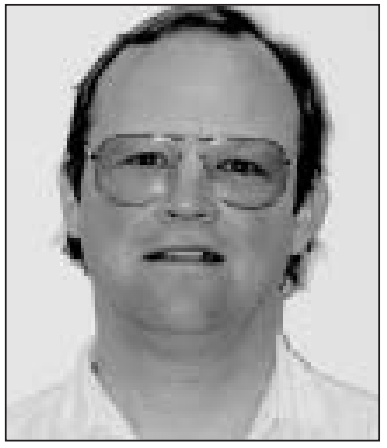

S. Craig DeLong

\section{Introduction}

The use of our knowledge of natural disturbance dynamics as a basis for forest management policy directed towards maintaining biological diversity has increased steadily (Booth et al. 1993, BC MOF and BC MOELP 1995, Harvey et al. 2002). The underlying assumption is that the forest biota is adapted to the conditions created by natural disturbances and thus should cope more easily with the ecological changes associated with forest management activities if the pattern and structure created resemble those of natural disturbance (Hunter 1993, Bunnell 1995, Angelstam 1998).

For various reasons, past forest management policies and guidelines have set somewhat arbitrary limits. These limits were often related to meeting timber volume targets, addressing perceived public concerns, or creating conditions that favoured certain organisms (e.g., ungulates). Limits were often stated for landscape or stand attributes such as patch size, species composition, stand density, non-forested area, and soil disturbance. Although well-meaning and easily administered, these practices result in patterns bearing little relationship to those created by natural disturbance dynamics. Studies of natural disturbance in the boreal forest have demonstrated large ranges in disturbance patch size (Eberhart and Woodward 1987, DeLong and Tanner 1996), tree density (DeLong and Kessler 2000), and volume of coarse woody debris (Clark et al. 1998, DeLong and Kessler 2000). Adopting forest management practices that approximate the natural range of variability is being widely accepted as an appropriate way to manage for the needs of many organisms.

The Biodiversity Guidebook (BC MOF and BC MOELP 1995) was the first attempt in British Columbia to guide forest management based on the natural disturbance template. Specific guidance for seral stage distribution, patch size, wildlife tree patch amount, and spatial arrangement and more general guidance on species composition and stand structure were included in this guide. Since the completion of the Biodiversity Guidebook, more information on natural disturbance dynamics has become available. Within northeastern British Columbia, a number of studies have investigated particular aspects of natural disturbance (e.g., DeLong 1998, DeLong and Kessler 2000, Lewis and Lindgren 2000, DeLong et al. 2003).

This paper outlines landscape and stand management goals based on the "natural range of variability" concept and demonstrates how these goals have been modified to meet

${ }^{1}$ Ministry of Forests, 1011 4th Ave., Prince George, British Columbia V2L 3H9. E-mail Craig.Delong@gov.bc.ca 
other societal goals for developing sustainable management plans for large landscapes within northeastern British Columbia. This paper also describes how studies of natural disturbance can be used to assist in developing and implementing ecologically sensitive sustainable forest management plans.

\section{Developing Ecologically Based Landscape Units}

Instead of adopting the Natural Disturbance Types (NDTs) presented in the Biodiversity Guidebook (BC MOF and BC MOELP 1995), the Prince George Forest Region was divided into nine Natural Disturbance Units (NDUs) (Fig. 1). These units were felt to better separate areas based on differences in disturbance processes, stand development, and temporal and spatial landscape disturbance pattern. In drawing the boundaries of the NDUs, the subzone level of the zonal classification of the biogeoclimatic ecosystem classification (BEC) (Pojar et al. 1987) was used to help delineate areas of relatively homogeneous macroclimate. The zonal classification breaks the landscape into biogeoclimatic (BGC) units, which are classes of geographically related ecosystems that are distributed within a vegetationally inferred climatic space (Pojar et al. 1987). BGC units had previously been shown to be linked closely to differences in natural disturbance rate and patch size (DeLong 1998).

In addition to the BGC unit maps, the estimated distribution of old forest in the absence of harvesting was mapped to assist in drawing the boundaries of the NDUs. To do this, we identified all areas that the current forest inventory indicated were more than 140 years old or had been harvested. Harvested stands were assumed to have been generally over 140 years old. This relative amount of old forest map was used along with the BGC lines for drawing boundaries between areas with assumed different fire cycles based on the relative amount of old forest present. There was general agreement between the BGC units and relative amount of old forest map but the BGC-delineated units were modified in four main ways for practical application.

1. BGC units were lumped where estimated disturbance cycle, based on methods described in DeLong (1998), was within 30 years, and general tree species composition and topography were similar.

2. Some BGC units were split into their montane and plateau portions, based on the finding of DeLong (1998) that macrotopography can significantly influence disturbance rate and patch size.

3. Small high elevation areas (i.e., $<500$ ha) mapped as a different BGC unit than the surrounding area were often amalgamated with the surrounding unit especially if the amount of old forest appeared similar to the surrounding unit.

4. Fine-scale adjustments to boundaries were made to follow administrative units if the adjustments were felt not to compromise the ecological intent of the boundary.

One purpose of the modifications was to create units that were many times larger than the largest potential natural disturbance (i.e., 100 000-ha fires in most plateau sub-boreal and boreal landscapes), because attaining stability for natural disturbance cycles may only be theoretically possible at larger spatial scales (Baker 1989). The modifications were also intended to reduce the number of units with different man- agement guidance while ensuring that important differences in large-scale disturbance patterns were recognized. Some NDUs were subdivided into low elevation (e.g., valley, plateau) and upper elevation (i.e., mountain) due to differences in climate, disturbance history, or succession. These subdivisions (subunits) are not shown on the map (Fig. 1), but correspond to existing BGC zones. To develop certain policies (i.e., old-forest requirements), the subunits were split into the smaller BGC units. This paper does not deal with this level of division.

\section{Developing Disturbance-Based Management Guidance}

The guidance developed for each NDU subunit (NDS) was developed for management of seral stage distribution, patch size distribution, patch shape, and vegetation species composition and structure. Most of the guidance relates to approximating wildfire as it was the key stand replacement disturbance agent in most NDUs and the one that we have exhibited the most control over (DeLong and Tanner 1996, DeLong 1998). In effect, wildfire is the disturbance process we are generally attempting to replace with harvesting.

\section{Seral stage distribution}

Forests of differing age since stand-replacement disturbance have different structural and functional values (Franklin et al. 2002). Old-growth forests, the most obvious example of this, are considered valuable in maintaining biological diversity, as wildlife habitat, as a benchmark for forest management, and for aesthetic and intrinsic reasons (MacKinnon 1998, Vallauri et al. 2001). Recently killed forests or young natural forests also appear to provide important habitat for some organisms. For example, Black-Backed Woodpeckers (Picoides arcticus [Swainson]) are commonly associated with standing dead forests and may require recently burned forests for their longterm persistence (Hutto 1995, Hoyt and Hannon 2002). Achieving similar distribution of seral stages seems to be an important objective for ecosystem management. Focusing on young natural and old forest seems to be appropriate since mid-aged forest is likely to be abundant in managed landscapes.

The natural range in variability (NRV) for different-age forests for each NDS was established using the estimated stand replacement disturbance cycle and a simulation model. Disturbance cycle, usually fire cycle, for each NDS was either obtained directly from the literature, if local data were available (DeLong 1998), or from adjacent forested landscapes that had a similar disturbance history. Once a disturbance cycle was assigned to the NDS, the NRV was calculated using a simple stochastic landscape model implemented in SELES (Spatially Explicit Landscape Event Simulator) (Fall and Fall 2001).

One, or combinations, of three main strategies for management of old forest are recommended for each NDS depending on the natural disturbance rate and the historical temporal, and spatial distribution of old forest. In landscapes with 1) high natural disturbance rates (e.g., disturbance cycle $<150$ years), 2) generally even-aged stands dominated by early seral species, and 3) few patches of very old forest $(>200$ years) but large patches of older forest ( $>120$ years), a system of "rotating reserves" is recommended. In this strategy, large patches (> $100 \mathrm{ha}$ ) of older forest are identified to fulfil a per- 


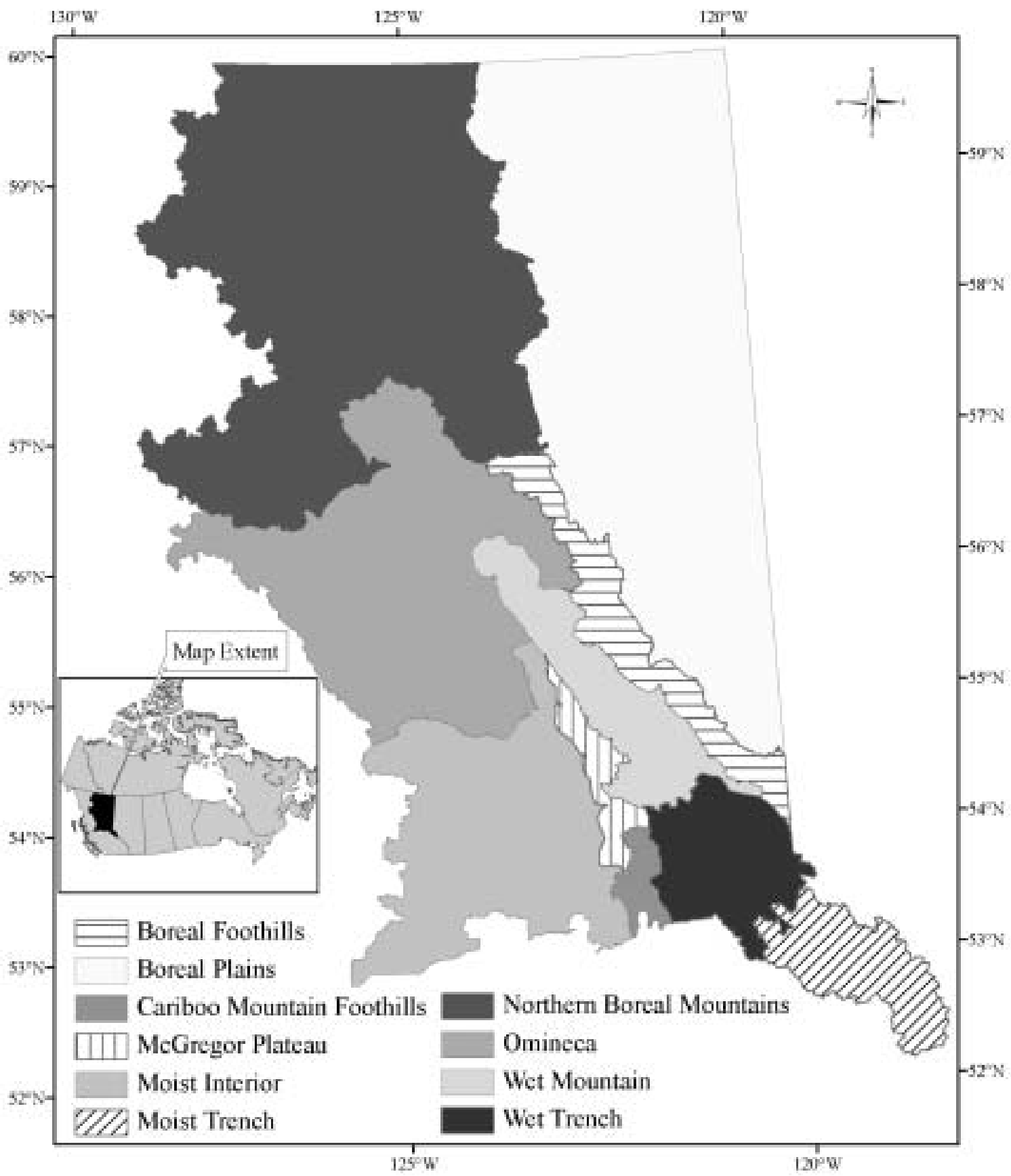

Fig. 1. Study area showing distribution of Natural Disturbance Units.

centage (e.g., > 50\%) of the total old forest requirements. These reserves would be scheduled for harvest when reserve area(s) of roughly equivalent value and size have been identified to take their place. The intent is to always have some large reserves of forest that are old but not so old (e.g., > 200 years old) as to be "unnatural" and highly susceptible to standreplacement forest insect or disease outbreaks. Whenever possible the reserves chosen to replace existing ones should be stands that originated from a natural event (e.g., wildfire) that occurred in a natural stand. Such stands are more likely to contain higher levels of deadwood and be structurally more complex than managed stands.

In landscapes where large fires were common but the disturbance cycle was roughly 150-300 years, a strategy of irregularly dispersed large permanent reserves is recommended. This may result in some areas (e.g., watersheds) having a large amount of old-forest reserve and adjacent areas with much less. This strategy approximates the natural condition, in these landscapes, where at any one time a large fire may have consumed most of the forest in one watershed, while in an 
adjacent watershed much of the forest may have escaped fire for over 150 years. The more uneven-aged old forests in these landscapes are less susceptible to stand-replacement fire and pest outbreaks and therefore have a higher likelihood of maintaining old-forest structure over a long time. Replacement may be necessary but not continuously, as in the rotating reserve strategy.

In landscapes where large fires were rare (i.e., fire cycle $>$ 300 years) and old uneven-aged forests dominate the landscape, a strategy of regularly dispersed and connected permanent reserves is recommended. In this case all watersheds would contain a large amount of old forest. The focus would be to manage the forest in a manner that would least disrupt the matrix old forest and the functions it performs. Some amount of partial cutting may be appropriate in the matrix old forest, but only if that type of harvesting clearly maintains functionally important old growth structures. An additional caution is that required access structures (e.g., roads, landings) needed to conduct partial cutting may significantly reduce the functional value of these harvested areas especially where continued human motorized access is available.

Young natural forest is more difficult to manage since it is hard to predict when, where, and how much young natural forest will be created on the landscape. In landscapes where there is currently an abundance of young natural forests, such as on the Moist Interior-Plateau NDS where there is an outbreak of mountain pine beetle (MPB) (Dendroctonus ponderosae [Hopkins]), the goal may be to achieve a natural forest target made up of young natural-origin stands and old-forest stands dominated by non-susceptible species. Young natural forest has been shown to have some of the same habitat values (e.g., woodpecker habitat [Hoyt and Hannon 2002]) as old forest. In landscapes (i.e., NDSs) where there is limited stand-replacement disturbance due to fire control, limiting salvage of smaller patches of young forest killed by natural events is suggested. However, if these strategies result in young natural forest amounts well below historic levels, a longer-term strategy that includes prescribed burning may be required.

Intensive forest management may be used as a tool to increase the area available for maintaining natural forests by reducing the landbase required to achieve a desired harvest yield. Any strategy that can improve the volume yield or value yield for particular sites means that a desired harvest level can be achieved from a smaller landbase, resulting in more area that can be used to protect natural forest values. This strategy has particular merit in areas where sites are very productive and easily managed, such as the Wet Trench NDU (Fig. 1).

Patch size distribution, block design, and species composition Managing for a more natural patch size distribution that would include a large proportion of harvested forest in patches exceeding 100 ha appears to have some important ecological benefits. Apart from resulting in a more natural spatial age mosaic on the landscape, it slows the rate of new road building, new stream crossings, and snag depletion (DeLong et al. 2004). Allowing some large patches also reduces fragmentation, which has been shown to have a negative impact on species such as American marten (Martes americana [Turton]) in forested landscapes (Chapin et al. 1998, Hargis et al. 1999).

Table 1. Recommended shape indexa for different size openings based on examination of shape index of natural wildfires by DeLong and Tanner (1996).

Opening size (ha)

$\begin{array}{cc}50-100 & 1.5-2.5 \\ 100-500 & 2-3.5 \\ >500 & >2.5\end{array}$

aShape Index $=\mathrm{p}_{\mathrm{x}} / 2 \sqrt{\pi} \cdot \sqrt{ }\left[\mathrm{a}_{\mathrm{x}} \cdot 10000\left(\mathrm{~m}^{2} \mathrm{ha}^{-1}\right)\right]$ where $\mathrm{a}=$ area of opening, and $\mathrm{p}=$ perimeter of opening (Patton 1975).

In landscapes where fire control has had a significant impact (i.e., all landscapes within the study area, based on the last 40 years of fire records), this control will have reduced large patches but increased small patches, since it stops some small fires from getting larger. In these areas, it is suggested that harvested patches should be designed to take the place of medium- to large-disturbance patches that historically were created by fire. Small patches can be effectively managed by not harvesting small-patch disturbances or harvesting only within their boundaries.

Harvesting can never completely duplicate the effects of fire but it can approximate certain characteristics of fire such as size, shape, and fire skips. Some other characteristics such as variable disturbance intensity can be partially managed for.

The shape of fires is more complex than past harvest openings (DeLong and Tanner 1996). Table 1 contains suggested targets for block shape complexity based on wildfires examined by DeLong and Tanner (1996). In the past, it was not practical to lay out blocks with complex shapes using compass and chain. However, global positioning systems and geographic information systems allow for the practical implementation of more complex block shapes. DeLong (1999) has detailed information on design of blocks to approximate wildfire. $^{2}$

Fire skips are consistently found within the boundaries of fires (Eberhart and Woodward 1987, DeLong and Tanner 1996) and appear to be an important landscape element in disturbed landscapes (DeLong and Kessler 2000). The ecological importance of retaining mature forest patches or individual trees within clearcuts has been demonstrated for various organisms (Sillett and Goslin 1999, Tittler et al. 2000, Côté and Ferron 2001). Currently, an average of approximately $10 \%$ of the area within a harvest opening is left in fixed-width riparian reserves or wildlife tree patches within the study area. Increasing the proportion of harvest area left in reserves and the average reserve size as forest harvest patch size increases is recommended, consistent with the trend demonstrated for wildfires (DeLong and Tanner 1996).

Wildfire intensity varies considerably over the extent of a wildfire event. The impact within a fire boundary can vary from none (i.e., fire skips) to considerable, where all trees are killed and most of the forest floor is removed. This variation in intensity provides for considerable variation in vegetation pattern (Carleton and MacLellan 1994, Schimmel and

${ }^{2}$ DeLong, C. 1999. Natural disturbance block design workbook. BC Min. For., Prince George, BC. Unpublished internal report. 16 p. 


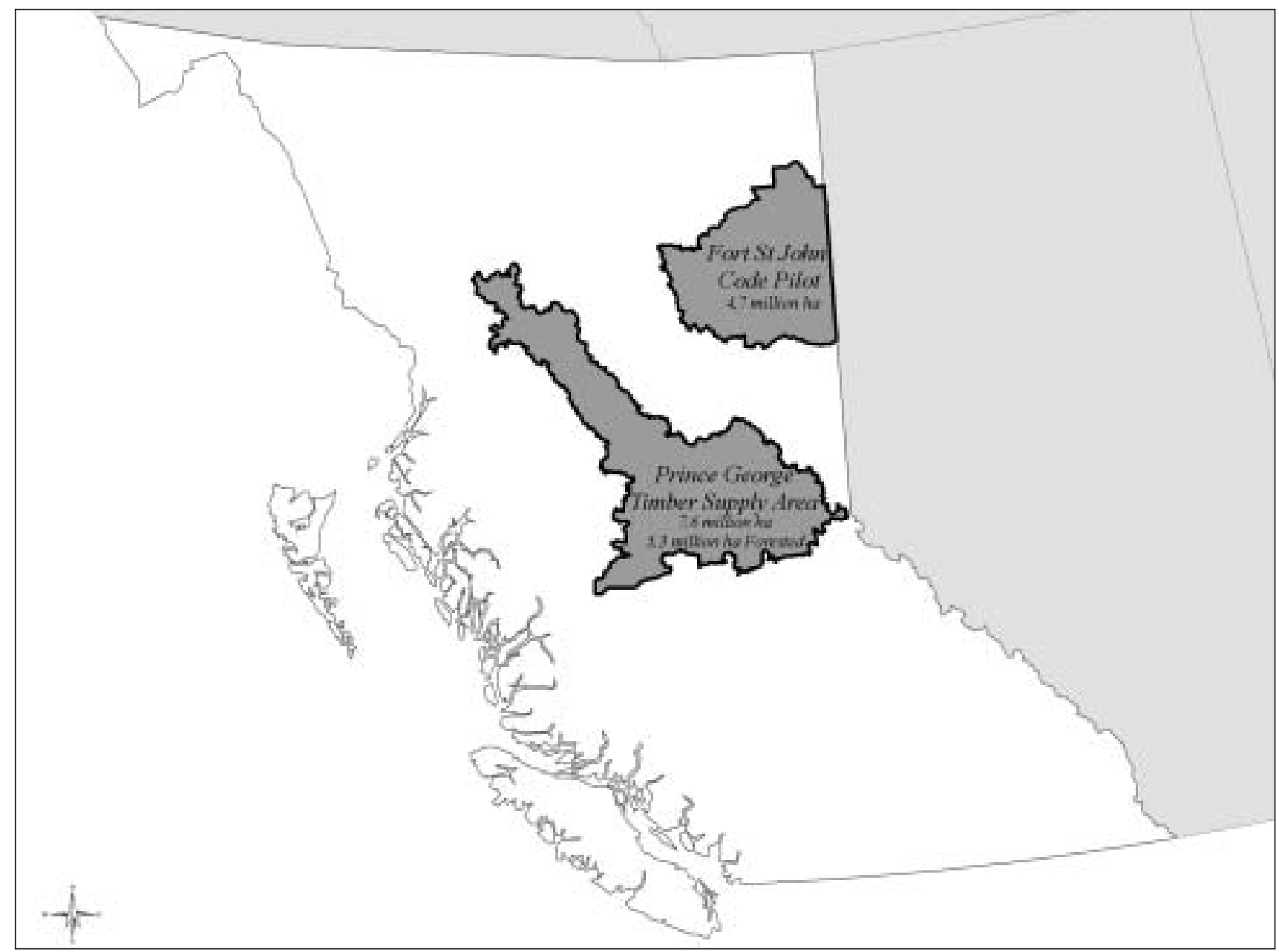

Fig. 2. Outline of two areas where implementation of guidance and policy based on natural disturbance-based managed has occurred.

Granstrom 1996). In fire skips the vegetation will remain relatively unchanged, whereas in other areas the resulting vegetation is a product of remaining live tissue, buried live seed, seed transported from adjacent live seed sources, and site conditions. Any attempt to create similar vegetation patterns after harvest will be crude but similar proportions of non-forest (e.g., willow, alder) and forested habitat types and forests of similar tree composition and structure are suggested.

\section{Implementation of Guidance}

To implement natural-disturbance-based management (NDBM), it is necessary to determine tradeoffs with other values and set objectives that can be reasonably achieved. To date, objectives have been developed and are currently being implemented by joint government industry groups in two large areas (Fig. 2). I will describe the guidance and policy developed for one of those areas, the Prince George Timber Supply Area (PGTSA).

In 2002 the Landscape Objectives Working Group (LOWG) was formed to develop landscape- and stand-level guidance for management of biodiversity within the PGTSA. Its first task was to develop NDBM guidance and policy relating to three objectives: old forest, interior old forest, and patch size.

\section{Old forest}

Since management of old forest requires either no harvest reserves, or areas where significantly less timber volume is removed over time (e.g., partial cutting or long rotations) there is an impact on the amount of harvest or allowable annual cut. Fortunately, in the wet mountain landscapes (e.g., Wet Mountain NDU, Wet Trench NDU; Fig. 1), which have high old-forest requirements, the potential impact is reduced through a large contribution of old forest from the non-contributing landbase (i.e., forest outside of the timber harvesting landbase; Table 2). A key question, however, is how well the non-contributing landbase represents the ecological diversity of old forests in the landscape.

To examine the impact of implementing targets based on the NRV estimates, the LOWG conducted an aspatial timber supply analysis over the PGTSA (Fig. 2). The PGTSA has a gross area of 7.5 million ha, 3.4 million of which are in the timber harvesting landbase. The timber supply analysis was conducted following standard timber supply review procedures in use in British Columbia as outlined in the Prince George Timber Supply Analysis Report (BC MOF 2001).

The first step in this analysis was to match the current base case for timber supply in place due to the current MPB out- 
Table 2. Area of timber harvesting and non-contributing landbases, estimated percentage of total forested area in forests greater than 140 years old for natural forests, and targets for managed forests under three different scenarios for Natural Disturbance Subunits in the timber supply modelling exercise.

\begin{tabular}{|c|c|c|c|c|c|c|}
\hline \multirow[t]{2}{*}{ Natural Disturbance Subunit } & \multirow{2}{*}{ 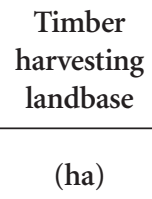 } & \multirow{2}{*}{$\begin{array}{c}\begin{array}{c}\text { Non- } \\
\text { contributing } \\
\text { landbase }\end{array} \\
\text { (ha) }\end{array}$} & \multirow{2}{*}{$\begin{array}{c}\mathrm{NRV}^{\mathrm{a}} \text { for } \\
\text { forest } \\
>140 \text { years } \\
\text { (\% of total } \\
\text { forested area) }\end{array}$} & \multicolumn{3}{|c|}{$\begin{array}{c}\text { Scenario target } \\
>140 \text { years } \\
(\% \text { of total forested area })\end{array}$} \\
\hline & & & & $1^{b}$ & 2 & 3 \\
\hline McGregor Plateau & 217807 & 78325 & $43-61$ & $11-34$ & 43 & 26 \\
\hline Moist Interior-Mountain & 135313 & 58720 & $41-61$ & $14-42$ & 41 & 29 \\
\hline Moist Interior-Plateau & 1543574 & 604199 & $17-33$ & $11-34$ & 12 or 17 & 12 or 17 \\
\hline Northern Boreal Mountains & 81401 & 121849 & $37-60$ & $14-42$ & 37 & 37 \\
\hline Omineca-Mountain & 300123 & 250027 & $58-69$ & $14-42$ & 58 & 58 \\
\hline Omineca-Valley & 593672 & 186942 & $23-40$ & $11-34$ & 23 & 16 \\
\hline Wet Mountain & 552936 & 221903 & $84-89$ & $15-54$ & 84 & 50 \\
\hline Wet Trench-Mountain & 97997 & 212637 & $80-88$ & $19-54$ & 80 & 48 \\
\hline Wet Trench-Valley & 292046 & 158657 & $76-84$ & $17-51$ & 76 & 53 \\
\hline
\end{tabular}

${ }^{\mathrm{a}} \mathrm{NRV}=$ Natural range of variability.

${ }^{\text {b}}$ Target varies by landscape unit depending on emphasis (i.e., low, intermediate, or high biodiversity emphasis). See BC MOF and BC MELP (1995, 1999) for more details.

break, which calls for an increase (uplift) in allowable annual cut from the previous base case over the first 70 years (Scenario 1). The analysis then shifted to determining the impact on the short- and long-term harvest flow of different scenarios based on meeting NRV targets. One scenario tried to meet the average of the estimated NRV for forests over 140 years old (not shown) and another attempted to meet the minimum estimate of NRV (Scenario 2). An additional 11 scenarios, which represented tradeoffs between meeting some target based on NRV and timber supply impact, were conducted. The LOWG evaluated each and chose a final scenario (Scenario 3) to be presented to the decision-makers. The range in estimated NRV of forests over 140 years old and proposed targets for forest over 140 years old for the three scenarios is shown in Table 2.

The reduction in the long-term sustained allowable annual cut for Scenario 2 was $18 \%$ and $1.4 \%$ for Scenario 3. The decision maker adopted Scenario 3, which was used to set old-forest requirements within the PGTSA (BC MSRM 2004a).

\section{Interior old forest}

The reduction of old forest that is unaffected by edge or "interior old forest" is often a consequence of forest fragmentation from dispersed harvesting (DeLong and Tanner 1996). Forest fragmentation has been demonstrated to adversely impact American marten (Chapin et al. 1998, Hargis et al. 1999) and woodland caribou (Rangifer tarandus ssp. caribou [Gmelin]) (Smith et al. 2000).

Estimates of the patch size of old forest in natural landscapes has been shown to be heavily skewed to patches larger than 200 ha (Andison 2003). Unpublished data from northeastern British Columbia show that patches larger than 1000 ha are common in both NDUs that have short fire return intervals (e.g., Boreal Plains) as well as longer fire return intervals (e.g., Boreal Foothills and Wet Mountain) (Fig. 3).
The amount and patch size of interior old forest was determined by the LOWG in the PGTSA to establish some reasonable objectives for its management. Interior old forest was considered to be any forest more than 140 years old that was more than $200 \mathrm{~m}$ away from an abrupt forest edge. This is a liberal estimate of the edge effects based on data for northern British Columbia (Burton 2001, 2002). An abrupt forest edge was considered to be lodgepole pine or deciduous-dominated stands that were less than 61 years old, stands dominated by other species that were less than 81 years old, primary access roads, pipelines, railways, and hydro transmission corridors. Further details can be found in the PGTSA Landscape Objective Working Group Background Report (British Columbia Ministry of Sustainable Resource Management 2004b).

Based on recent data for wetter NDSs (e.g., Wet Mountain and Wet Trench - Valley), interior old forest appears to currently have a patch size distribution similar to that for old forest estimated for natural forest (Figs. 3, 4a, and 4b). However, fewer large patches of old forest appear in the current managed landscape in the drier Moist Interior-Plateau NDS (Fig. 4c). The Moist Interior-Plateau is assumed to have a patch size distribution of old forest similar to the Boreal Plains-Upland NDS, as both are areas with short fire return intervals and large fires. Whereas the Boreal Plains-Upland NDS had an estimated 36\% of old forest in patches greater than 1000 ha before harvest, the Moist Interior-Plateau NDS currently has $22 \%$ (Figs. 3 and 4 c). However, if patches of forest that are 120 to 140 years old are included in the analysis, the figure for the Moist Interior-Plateau NDS improves to $37 \%$. At the scale of the NDS the patch size of interior old forest is comparable with that estimated for the historic landscape. However, some of the larger patches of old forest in a managed landscape may not provide equivalent quality to those in an unmanaged landscape. Fig. 5 depicts two patches of old forest that both meet the interior forest objective and 


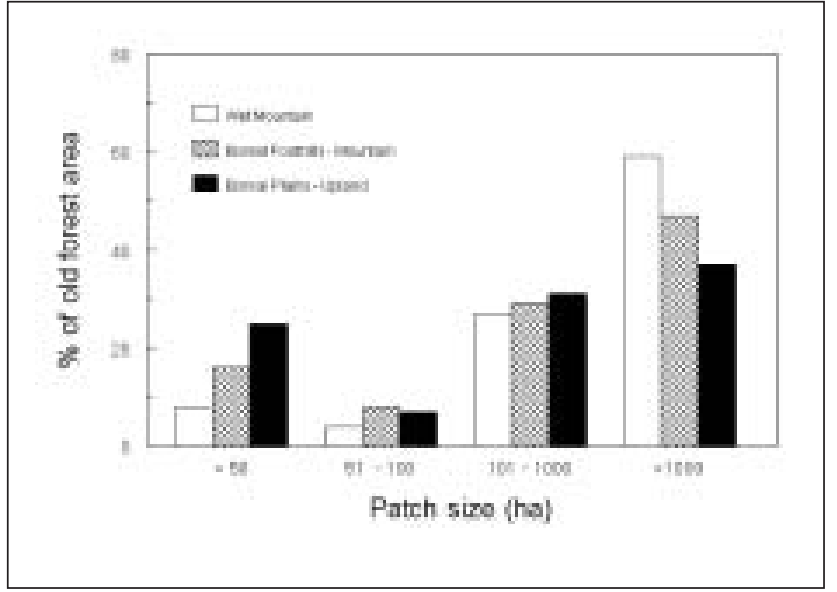

Fig. 3. Estimated patch size of old forest in 1960 (i.e., before logging) as a percentage of total old forest area for three Natura Disturbance Subunits in northeastern British Columbia (data reproduced with permission from Canfor Corp.].

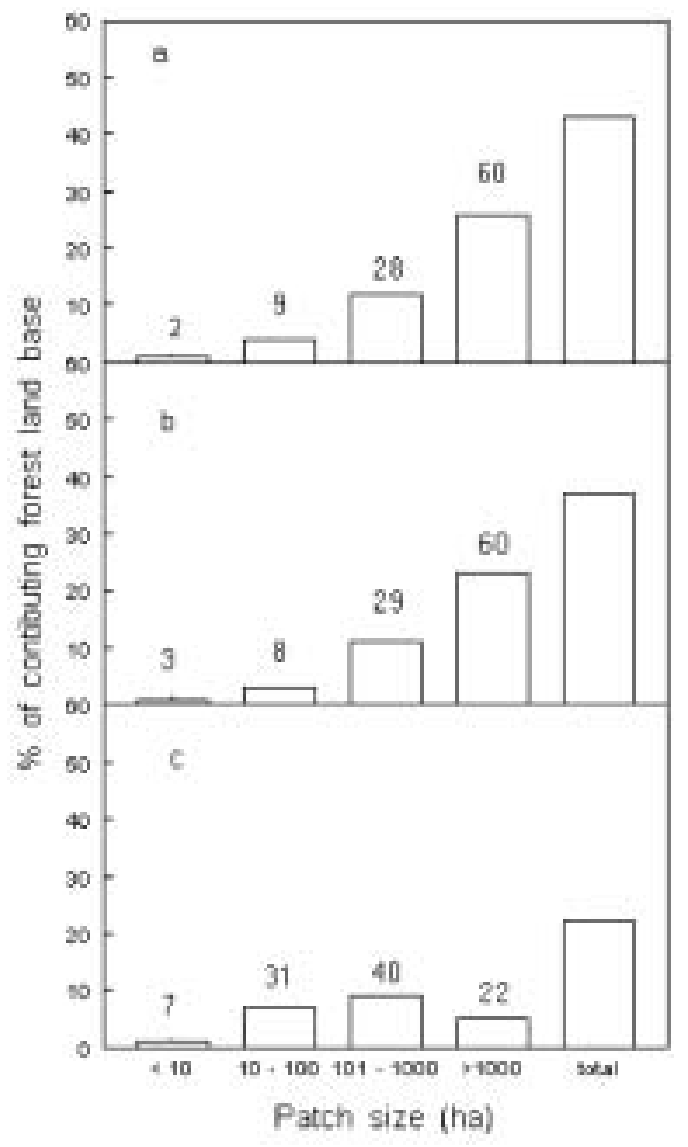

Fig. 4. Patch size distribution of old interior forest as a percentage of the contributing forest landbase for the a) Wet Trench-Valley, b] Wet Mountain, and c] Moist Interior-Plateau Natural Disturbance (Sub-)units. (Note: data above bars are percentage of total old interior forest.]

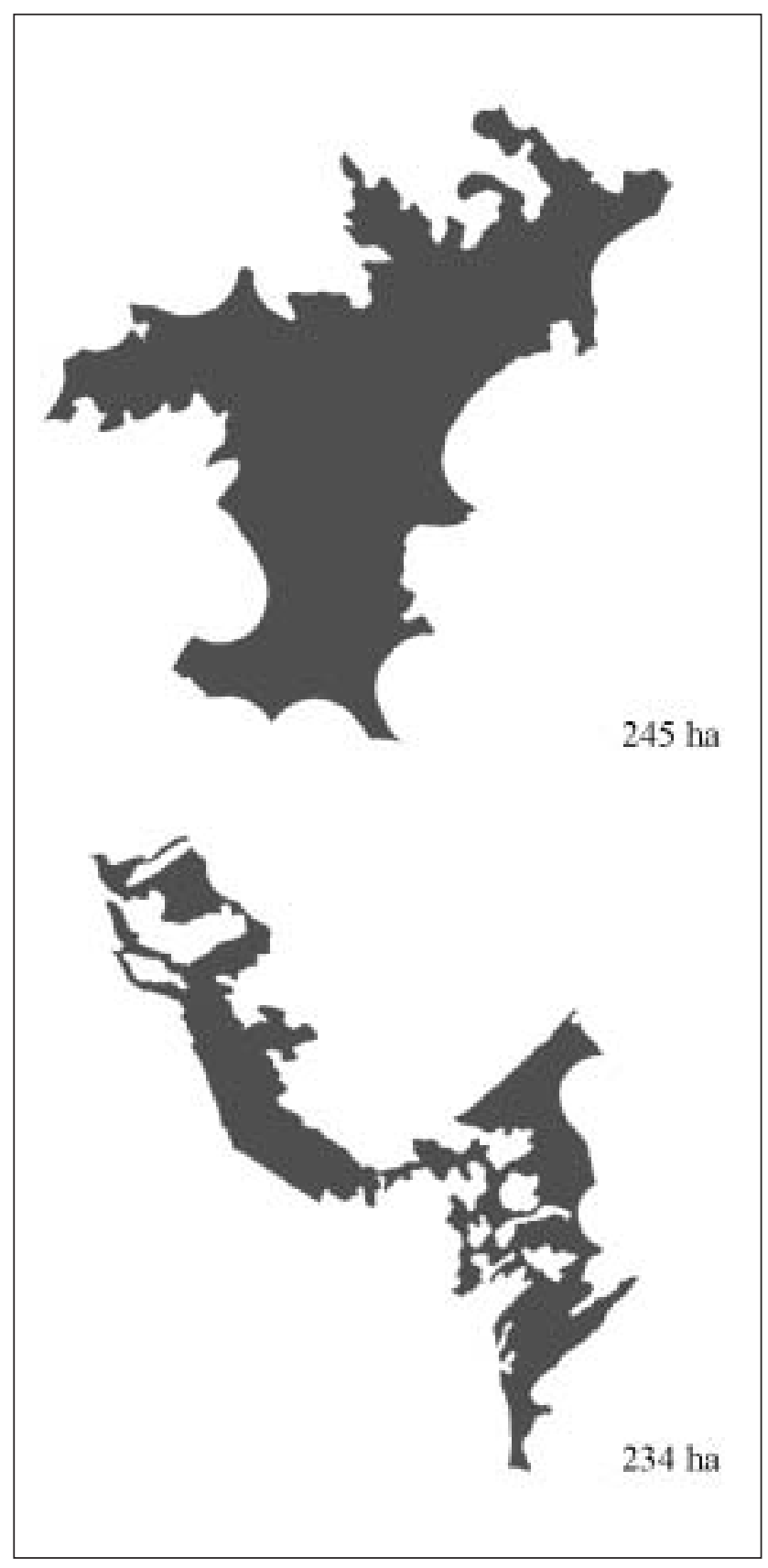

Fig. 5. Illustration of two areas that both meet the definition of interior old forest developed by the Landscape Objective Working Group for the Prince George Timber Supply Area. The one on the right illustrates the disruption of continuity due to dispersed block harvest.

are of similar area. The one area that is disrupted by harvest blocks is unlikely to have similar habitat value for certain organisms as the one that is less disrupted. Thus, efforts must be made to choose reserves that contain the highest quality of old forest based on factors such as minimum disruption by harvest and greatest distance from roads. Currently, the legal requirement for interior old forest in the PGTSA is $10 \%, 25 \%$, or $40 \%$ of total amount of old forest depending on history of past fragmentation and estimated natural degree of connectedness of old forest for the NDS. 


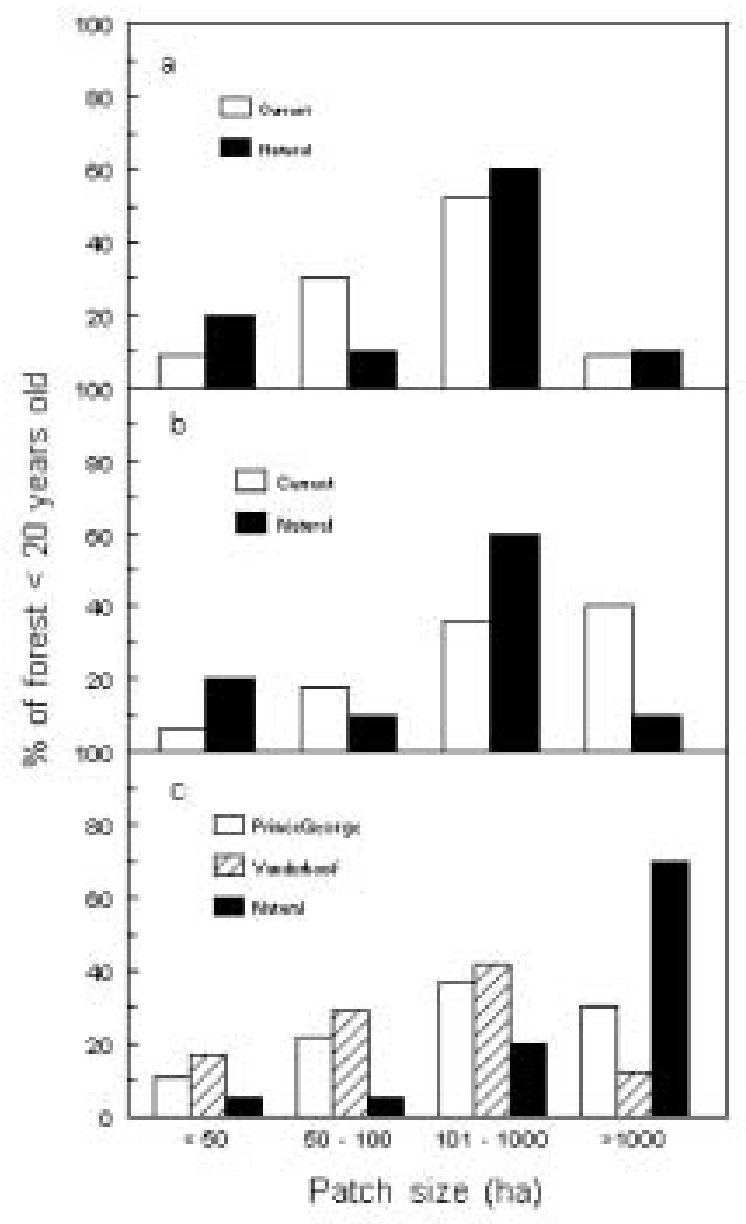

Fig. 6. Patch size distribution of forest less than 20 years old for a) Wet Mountain, b] Wet Trench-Valley, and c) Moist InteriorPlateau Natural Disturbance (Sub-) units compared with estimated natural patch size distribution adapted from DeLong (1998). Two forest districts are compared in c) to show the effect of location.

\section{Patch size of young forest}

Differences in patch size distribution for recent harvest openings were compared with those created by natural disturbance for all NDSs (Fig. 6). The largest differences were evident for landscapes where the prescribed dispersed mid-sized (i.e., 50-100 ha) block pattern had been least altered by the need to manage windthrow or pest outbreaks (e.g., Vanderhoof Forest District in the Moist Interior-Plateau NDS; Fig. 6c). In other words, the planned openings were the ones most contributing to creating an unnatural landscape pattern. Patches larger than 1000 ha were more common in the natural versus managed landscape for Moist Interior-Plateau NDS, but the reverse was true for the Wet Trench-Valley NDS (Fig. 6b and 6c). This is due to large fires and dispersed harvest being more common in the drier Moist Interior - Plateau NDS versus less large fires and large valley bottom harvest openings primarily for spruce beetle (Dendroctonus rufipennis [Kirby]) and western hemlock looper (Lambdina fiscellaria ssp. lugubrosa [Hulst]) salvage harvest in the Wet Trench - Valley NDS. The current patch size policy is to trend towards a more natural landscape pattern over time. Some of the specific ways this will be achieved are to 1) amalgamate existing dispersed blocks into naturally shaped larger openings, 2) design large openings in areas of pest outbreaks with retention patches of non-host tree species, and 3) not salvage harvest small patches of windthrow or burned areas. To evaluate how well this is being accomplished, the current suggestion is to have forest licensees submit the planned next two years of harvest opening sizes for each NDS along with a strategy for moving towards a more natural patch size distribution and a rationale for any significant departure from this strategy. Mechanisms and policy regarding acceptance of a harvest patch size plan are currently being developed.

\section{Conclusion}

Although there is increasing recognition that NDBM is desirable in an attempt to maintain natural levels of biodiversity and ecosystem functions (Angelstam 1998, Harvey et al. 2002, Crow and Perera 2004), such management is slow in being implemented on a large scale. This paper has provided an overview of a large body of work that resulted in the successful implementation of NDBM guidance over an extensive landbase. Based on the theory of natural disturbance emulation, this guidance should advance the maintenance of biological diversity in northeastern British Columbia. Since the processes followed resulted in practical application by forest practitioners and the management guidance was developed for a wide range of forest types, it will hopefully provide a template for future successful implementation of NDBM in other jurisdictions.

\section{Acknowledgements}

Tremendous thanks to the members of the Prince George Timber Supply Area Landscape Objectives Working Group for their belief in my work, and their dedication and persistence in helping me with the often difficult transition from research to application. All statements and data presented in the manuscript are the sole responsibility of the author. I also thank Dianne Roberge, Bruce Rogers, John Rustad, Frank Spears, Dave Tanner, and others I may have forgotten for their assistance with the data collection, analysis, and mapping used to develop natural-disturbance-based management guidance for the study area. Forsite Forest Management Consultants conducted the timber supply analysis reported in the manuscript. Andre Arsenault, Yves Bergeron, Sylvie Gauthier, and Dale Seip kindly reviewed earlier versions of this manuscript. Thanks to Stafferd Shuman for preparing some of the figures.

\section{References}

Andison, D. 2003. Patch and event sizes on foothills and mountain landscapes of Alberta. Foothills Model Forest, Hinton, Alberta. Alberta Foothills Disturbance Ecology Research Series Report No. 4. 61 p. Available at http://www.fmf.ca/ND/ND_report4.pdf.

Angelstam, P.K. 1998. Maintaining and restoring biodiversity in European boreal forests by developing natural disturbance regimes. J. Veg. Sci. 9: 593-602.

Baker, W.L. 1989. Landscape ecology and nature reserve design in the Boundary Waters Canoe Area, Minnesota. Ecology 70: 23-35.

Booth, D.L., D.W.K. Boulter, D.J. Neave, A.A. Rotherham and D.A. Welsh. 1993. Natural forest landscape management: A strategy for Canada. For. Can., Ottawa, ON. 16 p. 
British Columbia Ministry of Forests (BC MOF). 2001. Prince George Timber Supply Area analysis report. BC Min. For., Victoria, BC. Available at http://www.for.gov.bc.ca/hts/tsa/tsa24/tsr2/analysis.pdf.

British Columbia Ministry of Forests (BC MOF) and British Columbia Ministry of Environment, Lands and Parks (BC MELP). 1995. Biodiversity guidebook, September 1995. Forest Practices Code of British Columbia. Victoria, BC. Available at http://ilmbwww.gov.bc.ca/ilmb/lup/srmp/background/docs/LUGuide.pdf.

British Columbia Ministry of Forests (BC MOF) and British Columbia Ministry of Environment, Lands and Parks (BC MELP). 1999. Landscape unit planning guide, March 1999. Forest Practices Code of British Columbia. Victoria, BC. Available at http://www. for.gov.bc.ca/tasb/legsregs/fpc/fpcguide/biodiv/biotoc.htm.

British Columbia Ministry of Sustainable Resource Management (BC MSRM). 2004a. Order establishing landscape biodiversity objectives for the Prince George Timber Supply Area, October 2004. BC Ministry of Sustainable Resource Management, Prince George, BC. Available at http://ilmbwww.gov.bc.ca/lup/srmp/northern/ prince_george_tsa/pg_tsa_biodiversity_order.pdf.

British Columbia Ministry of Sustainable Resource Management. 2004b. Landscape Objective Working Group Prince George Timber Supply Area landscape level biodiversity objectives April 2004. BC Ministry of Sustainable Resource Management, Prince George, BC. Available at http://ilmbwww.gov.bc.ca/lup/srmp/northern/prince george_tsa/pg_tsa_biodiversity_order_bkgrnd_report.pdf.

Bunnell, F.L. 1995. Forest-dwelling vertebrate faunas and natural fire regimes in British Columbia. Conserv. Biol. 9: 636-644.

Burton, P.J. 2001. Response of vascular vegetation to cutblock edges in the Sub-Boreal Spruce zone of northwest-central British Columbia. Presented at the Annual Meeting of the Canadian Botanical Association, 25-27 June 2001, Kelowna, BC.

Burton, P.J. 2002. Effects of clearcut edges on trees in the Sub-Boreal Spruce zone of northwest-central British Columbia. Silva Fenn. 36: 329-352.

Carleton, T.J. and P. MacLellan. 1994. Woody vegetation responses to fire versus clear-cutting logging: A comparative survey in the central Canadian boreal forest. Ecoscience 1: 141-152.

Chapin, T.G., D.J. Harrison and D.D. Katnik. 1998. Influence of landscape pattern on habitat use by American marten in an industrial forest. Conserv. Biol. 12: 1327-1337.

Clark, D.F., D.D. Kneeshaw, P.J. Burton and J.A. Antos. 1998. Coarse woody debris in sub-boreal spruce forests of west-central British Columbia. Can. J. For. Res. 28: 284-290.

Côté, M. and J. Ferron. 2001. Short-term use of different residual forest structures by three sciurid species in a clear-cut boreal landscape. Can. J. For. Res. 31: 1805-1815.

Crow, T.R. and A.H. Perera. 2004. Emulating natural landscape disturbance in forest management - an introduction. Landscape Ecol. 19: 231-233.

DeLong, S.C. 1998. Natural disturbance rate and patch size distribution of forests in northern British Columbia: Implications for forest management. Northwest Sci. 72: 35-48.

DeLong, S.C., J.M. Arocena and H.B. Massicotte. 2003. Structural characteristics of wet montane forests in east-central British Columbia. For. Chron. 79: 342-351.

DeLong, S.C., S.A. Fall and G.D. Sutherland. 2004. Estimating the impacts of harvest distribution on building of roads, and snag abundance. Can. J. For. Res. 34: 323-331.
DeLong, S.C. and W.B. Kessler. 2000. Ecological characteristics of mature forest remnants left by wildfire. For. Ecol. Manage. 131: 93-106.

DeLong, S.C. and D. Tanner. 1996. Managing the pattern of forest harvest: lessons from wildfire. Biol. Conserv. 5: 1191-1205.

Eberhart, K.E. and P.M. Woodward. 1987. Distribution of residual vegetation associated with large fires in Alberta. Can. J. For. Res. 17: 1207-1212.

Fall, A. and J. Fall. 2001. A domain-specific language for models of landscape dynamics. Ecol. Model. 141: 1-18.

Franklin, J.F., T.A. Spies, R. Van Pelt, A.B. Carey, D.A. Thornburgh, D.R. Berg, D.B. Lindenmayer, M.E. Harmon, W.S. Keeton, D.C. Shaw, K. Bible and J. Chen. 2002. Disturbances and structural development of natural forest ecosystems with silvicultural implications, using Douglas-fir forests as an example. For. Ecol. Manage. 155: 399-423.

Hargis, C.D., J.A. Bissonette and D.L. Turner. 1999. The influence of forest fragmentation and landscape pattern on American martens. J. Appl. Ecol. 36: 157-172.

Harvey, B.C., A. Leduc, S. Gauthier and Y. Bergeron. 2002. Standlandscape integration in natural disturbance-based management of the southern boreal forest. For. Ecol. Manage. 155: 369-385.

Hoyt, J.S. and S.J. Hannon. 2002. Habitat associations of blackbacked and three-toed woodpeckers in the boreal forest of Alberta. Can. J. For. Res. 32: 1881-1888.

Hunter, M.L., Jr. 1993. Natural fire regimes as spatial models for managing boreal forests. Biol. Conserv. 65: 115-120.

Hutto, R.L. 1995. Composition of bird communities following stand-replacement fires in Northern Rocky Mountains (U.S.A.) conifer forests. Conserv. Biol. 9: 1041-1058.

Lewis, K.J. and B.S. Lindgren. 2000. A conceptual model of biotic disturbance ecology in the central interior of B.C.: How forest management can turn Dr. Jekyll into Mr. Hyde. For. Chron. 76: 433-443. MacKinnon, A. 1998. Biodiversity and old-growth forests. In J. Voller and S. Harrison (eds.). Conservation Biology Principles for Forested Landscapes. pp. 146-184. UBC Press, Vancouver, BC.

Patton, D.R. 1975. A diversity index for quantifying habitat "edge." Wild. Soc. Bull. 3: 171-173.

Pojar, J., K. Klinka and D.V. Meidinger. 1987. Biogeoclimatic ecosystem classification in British Columbia. For. Ecol. Manage. 22: 119-154.

Schimmel, J. and A. Granström. 1996. Fire severity and vegetation response in the boreal Swedish forest. Ecology 77: 1436-1450.

Sillett, S.C. and M.N. Goslin. 1999. Distribution of epiphytic macrolichens in relation to remnant trees in a multi-age Douglas-fir forest. Can. J. For. Res. 29: 1204-1215.

Smith, K.G., E.J. Flicht, D. Hobson, T.C. Sorensen and D. Hervieux. 2000. Winter distribution of woodland caribou in relation to clearcut logging in west-central Alberta. Can. J. Zool. 78: 1433-1440.

Tittler, R., S.J. Hannon and M.J. Norton. 2000. Residual tree retention ameliorates short-term effects of clear-cutting on some boreal songbirds. Ecol. Appl. 11: 1656-1666.

Vallauri, D., O. Gilg, L. Poncet and C. Schwoehrer. 2001. Références scientifiques sur la conservation d'un réseau représentatif et fonctionnel de forêts naturelles [Scientific references for a representative and functional conservation network of old growth forests]. World Wildlife Fund and Réserves Naturelles de France, Paris, France. 91 p. 